histogenesis and especially gametogenesis. It was a delightful, though distracting, experience to observe for the first time the beautiful mitotic figures of Lepidosiren in those days when Cambridge teaching was still sceptical regarding the existence of centrosomes! The value of Lepidosiren material for the investigation of celldetail is well brought out by the beautiful studies on the histogenesis of the blood by Bryce, on microgametogenesis by Agar, and on neurone relations by Ballantyne. The last-mentioned provides a typical case of new facts which, if they are really facts-and that they are facts, accurately described, I can personally testify-are shattering to one of the most sacred beliefs, for neurofibrils can be clearly seen to pass across the synaptic junction and plunge down into the cell-body of the next neurone.

Various ideas of a more general kind bearing on the principles of evolutionary theory have been inspired by these researches: that variability is to be regarded not as a phenomenon by itself but merely as one aspect of the general instability inherent in all living substance ; that the selection of variations in a definite direction necessarily involves the selection of the tendency to vary in that particular direction, and therefore necessarily results in 'orthogenesis'; that the phenomenon of parasyndesis discloses the existence of an attractive force which draws like chromatin together, and that this, while explaining the clumping together of like chromatin at successive points in the chromosome, renders unnecessary the assumption that the material basis of heredity consists of discrete and separate units or 'genes'.

Finally, I would urge, my prolonged experience in research has served to emphasize a consideration that is too often ignored, namely, that it is not sufficient to be content with making use of newly determined facts simply as arguments for or against already existing theories. On the contrary, it is essential that from time to time there should be a stock-taking, in which the body of relevant facts as now known is examined from a detached point of view, and the endeavour made by judicial consideration to arrive at a sound conclusion as to what general formula adequately fits the knowledge of to-day.

\title{
Food Storage and Research
}

$\mathrm{T}$ HE report of the Food Investigation Board describes the general activities of the Board and, in summary form, the scientific researches carried out by the members of the food investigation staff, under the general direction of $\mathrm{Mr}$. E. Barnard, the director of food investigation.* References are given to published work, but the special purpose of the report is to record the latest progress in those investigations which have not yet reached the stage at which full publication of the results is feasible.

Sir Joseph Barcroft was appointed chairman, on the resignation of Sir Frank Smith. Mr. Blackman, Prof. Hilditch and Sir Thomas Middleton were re-appointed members of the Board. Two special reports have been published, the first by $\mathbf{R}$. B. Haines, summarizing the more important data relating to the invasion of animal tissues by micro-organisms and their control (Special Report No. 45), and the second by C. H. Lea on rancidity in edible fats (Special Report No. 46).

Members of the food investigation staff paid visits to South Africa, Germany and the United States and Canada during the year. Broadly speaking, the impression which the Board has gained from the report on the American tour is

- Report of the Food Investigation Board for the year 1937. (Department of Scientific and Industrial Research.) Pp. 266+v. (London: H.M. Stationery Office, 1938.) 48. net. that while Great Britain is in no way behindhand in research on the handling and storage of foodstuffs, the application of science in this field is not so forward here as in the United States. There, the active belief of the leading industrialists in the value of research, and their keenness to apply scientific method and knowledge in the food industry were striking; and so was their readiness to spend large sums in developing new processes and in introducing new products to the public.

Reference is made in the report to the recommendation of the committee appointed to review the scope and form of the "Index to the Literature of Food Investigation", that this publication should be continued. The Board endorsed this recommendation and decided that the "Index" should cover the whole of the field which lies between the production of foodstuffs on one hand, and nutrition on the other hand; that it should be brought up to date as quickly as possible and should be published quarterly instead of halfyearly. In pursuance of this decision, the "Index" to the literature published in 1937 has now been issued, as vol. 9, Nos. 1-4. It is hoped to complete shortly vol. 7, No. 2 and vol. 8, which will deal with the literature published during 1935 and 1936.

From time to time, the Board is asked whether food that has been stored by modern methods, 
such as cold storage, gas storage or canning, is as nutritious as fresh food. The question was put to the Medical Research Council, who replied that in the present state of knowledge it is impossible to state categorically whether or not stored foods are as nutritious as fresh foods. Nor is it feasible to undertake research with the view of answering that question directly, since many years of intensive work on large groups of human beings would be necessary. Even then there would be little prospect of arriving at a definite decision, for, with further knowledge of the effects of dietary factors on nutritional processes, it would be found necessary to reconsider the results of the early years' studies in the light of fresh evidence. Nevertheless, useful information can be obtained by comparing the chemical composition of stored foods with that of fresh foods, and the general conclusion can be accepted that relatively little loss of known constituents occurs in foods stored by modern methods. Moreover, experiments on animals have shown that satisfactory nutrition can be maintained on diets composed solely of stored foods. In fact, food of good initial quality, stored by the best modern methods, is likely to be superior to similar food that, though still technically fresh, is in reality stale. Vitamin C and to a less extent vitamin $B_{1}$, however, are liable to be destroyed by heating.

The report of the Director of Food Investigation is divided as usual into sections dealing with the different foodstuffs and the engineering problems of food storage. Two considerable pieces of work were undertaken for the Herring Industry Board : the first dealt with the quality of kippers in relation to the quality of the fresh herrings from which they are made, and the second with the freezing and cold storage of herrings. The development of rancidity in the fat of herrings during cold storage is due to the action of certain enzymes, which are activated by common salt. Herrings frozen in brine need careful washing and glazing before storage : the possibility of satisfactory freezing in air is being explored.

Storage in ice will keep fish fresh for 10-12 days, a period which covers some two thirds of the trips made by British trawlers. Freezing in brine at $-20^{\circ} \mathrm{C}$. with storage at the same temperature or at $-30^{\circ} \mathrm{C}$. will keep white fish fresh for at least six months; lemon soles have been kept in a palatable condition for as long as two years. The fishing industry is now seriously considering the commercial possibilities of brine freezing and cold storage. It must, however, be emphasized that the fish should be absolutely fresh when frozen; it is of interest, therefore, to note that a simple chemical test for freshness, based on the estimation of volatile organic bases, appears promising. Accord- ing to the report, the dimethylamine content of the fish follows the bacterial curve very closely during spoilage, although the absolute amount present is much less than that of the triamine and ammonia. (See also Nature, Dec. 17, p. 1078.)

The increase in the hydrogen ion concentration which is essential to the proper keeping of the flesh of animals can only be ensured if an ample reserve of glycogen is present in the muscles at the moment of death. The practice of resting animals for at least twenty-four hours before slaughter is essential : it is also advisable to give a ration of easily absorbed food, such as cane sugar or glucose, rather than to withhold food completely during this period. Struggling on the slaughtering floor should also be reduced to a minimum ; estimations of lactic acid in the blood of slaughtered animals which have struggled show that an appreciable loss of acid may take place from glycogenolysis in the muscles; the acid in the blood will not contribute to the rise in muscle hydrogen ion concentration.

About two fifths of the report is devoted to the storage of fruit and vegetables. The study of the respiration of the apple has brought to light a new fact of practical importance. It appears that, in the stage before the attainment of full maturity at which the fruit is often gathered, namely, just before the onset of the climacteric rise in respiration, apples exhibit, on exposure to concentrations of carbon dioxide up to 15 per cent, a temporary increase in activity which may amount to as much as 100 per cent. Hence the possibility of carbon dioxide accumulating to dangerous levels is greater in the period immediately after the fruit has been put into store, especially if warm and respiring rapidly, than had hitherto been thought possible.

Experiments have been carried out on the cooling and storage of fresh strawberries for short periods. A temperature of $38^{\circ} \mathrm{F}$. was satisfactory for 2-3 days' storage, but $32^{\circ} \mathrm{F}$. gave more control over fungal rotting and would probably be necessary for longer storage. The rate of cooling affected the rate of subsequent deterioration. With slow air-speeds and a high relative humidity, no perceptible damage occurred in fruit cooled with air at either $23^{\circ}$ or $28^{\circ} \mathrm{F}$., provided the fruit was not allowed to freeze. A preliminary experiment on gas storage showed that the growth of fungal rots could be retarded without damage to the fruit by an atmosphere consisting of 10 per cent carbon dioxide, 10 per cent oxygen and 80 per cent nitrogen.

Other matters which are dealt with in the report are the storage of broccoli, the preservation of pears and asparagus by freezing, the effect of various methods of manuring, the storage properties of apples, the storage of hothouse grapes and the ripening of imported pears and plums. 